\title{
Understanding Generation Gap at Work Place
}

\author{
Dr. Harvinder Soni * Anagat Ashish** \\ * Professor (Management) Pacific College, PAHER University (Raj) India \\ ** Research Scholar (Management) Pacific College,PAHER University( Raj.) India
}

\section{Introduction}

\section{Generation Gap - A Reality at Work Place}

For the first time in the history of Indian organizations, employees from so many different age groups (within generation) are working side by side and employees like as young as their children and as old as their parent. Generation gap is a term popularized in western countries during 1960s referring to difference between people of younger generations and their elders, especially between children and parents. Although some generational differences have existed throughout history, modern generational gaps have often been attributed to rapid cultural change in the post-modern period, particularly with respect to such matters as fashion, digital technology, musical tastes, culture and politics. These changes are assumed to have been further magnified by the unprecedented size of the young generation which gave the power and inclination to rebel against societal norms.

Generation gap is defined as the differences found between members of different generation. More specifically a generation gap can be used to describe the differences in action, beliefs etc between members of young generation when compared to members of older generation.While generation gap of these gaps have been prevalent throughout all periods of history , the width (differences ) of these gaps have widened in the $20^{\text {th }}$ and $21^{\text {st }}$ century at work place.

\section{Key Differentiator- Aspiration}

It is aspiration that differentiates humans from other living things - and it is the power of aspiration that has given us mind boggling realities - no matter what the disparity. Studies have shown that age is as much with employees hopes, learning styles and expectations as to do with culture, gender and other characteristics. By understanding each generation and by giving employees what they thrive, managers can do more to enhance the employee productivity, morale, motivation, commitment, retention etc.

In earlier times, various multiple groups had worked together in the same Indian organization by virtue of hierarchical structure like old age group at the senior level, middle aged group at middle management level and younger employees at the junior management level. Interpersonal relations were mostly with peers and superiors thereby generational interactions were limited and restricted with organization structure , formality and authority. Seniors used to take decisions and communicate to the middle and junior management. There was no participation of middle/junior employees in the decision making. However such top down and leadership management practices are undergoing drastic change in professional organizations and are being reviewed with the entry of young employees.

\section{Bridging Generation Gap}

Generation Gaps in perspectives, attitudes, engagement and behaviours are nothing new to most discussed emerging popular concepts of Gen X and Gen Y. But these differences can significantly affect organization objectives if not properly aligned and effectively bridged by designing suitable HR processes. Lack of attention to such prevailing generational differences will create organizational brand equity less attractive to young recruits as well as older employees resulting in employee attrition leading to difficulty in finding right fit employees. The critical management skills will involve understanding generational differences in order to bridge and strengthen work relationships among employees. There is no other choice. Organizations need effective human resource process and system to attract and retain employees, regardless of vintage or range of skills.

Understanding of these two age groups fondly called as Gen $\mathrm{X}$ and Gen $\mathrm{Y}$ which are in majority at work place today, although Gen Y perceived antagonist on so many fronts, are actually coming together and can help organizations to become a great place to work. Understanding the overall behavioural patterns between these two generations is significant in the organization to evolve HR processes to enhance employee engagement and efficiency level. 


\section{Generation $\mathrm{X}$}

The term Generation X was coined by Magnum photographer Robert Capa in the early 1950s. He used it later as a title for a photo essay about young men and women growing up after world war II. The name Generation X was further popularized by Canadian author Donglas Coupland in 1991 - Generation X - Tales for Accelerated Culture concerning young adults and their life style. It was Deverson and Hemblett (1965) book Generation X - which has given lot of popularity. Dawson (2011) in a longitudinal study defined that people born between 1961 and 1981 are Gen X - who are highly educated, active, balanced, happy and family oriented. Various authors have concluded that a generation based worldwide on change, in search for dignity and individual freedom, the need for stability, love, tolerance, human rights for all. Compared with others, Gen $\mathrm{X}$ represents a more apparently heterogeneous generation - acknowledging social diversity. Thus , the Gen $\mathrm{X}$ encompasses the group of individuals born in the late 60's but before 80's really got started. They represent the pop culture of the 70's and often referred to as " latch key" kids - often left alone - which explains the independent resourceful and adaptive approach at work. Thus for the purpose of this study, Gen X have been classified by age as under:

$\begin{array}{llll}\text { Born Between } & : & & 1961-1980 \\ \text { Coming of Age } & : & 1988-1994 \\ \text { Age in 2016 } & & : & 55 \text { to } 36\end{array}$

Gen X occupies a very significant percentage of our workforce - although on gradual decline with advancement of age and retirement. They possess an entrepreneurial spirit, a do it yourself attitude and, in contrast to the generations before them, embrace change in the workplace. They are career oriented but place a strong emphasis on family time and strive for a good work - life balance. They look for freedom and autonomy they work to live rather than live to work. They brought up in an era of technological and social change. They possess a different work ethic, thrive on diversity, challenge, responsibility, honesty and creative input. A flexible work place is a must for a Gen X-er and they value constructive feedback - which both need to be taken into consideration while managing Gen $\mathrm{X}$.

Gen Y

Popularly known as the technological whiz kids in the generation world, these are born in the early 80 s thorough to the late 90s. They are estimated to occupy almost half of the working population in India by 2020 and around one third population in the world. They are also referred as Millenniums, classified by age as under.

$\begin{array}{lll}\text { Born between } & : & 1981-1995 \\ \text { Comings of Age : } & 1998-2006 \\ \text { Age in 2016 } & : & 36-21\end{array}$

Gen Y prefers to communicate through e-mails, instant messaging, blogs and text messages, rather than over the phone or face to face. They prefer to speak in tweets, update their statuses and upload the profile pics simultaneously. They prefer cyber training, webinars and telecommuting rather than traditional lecturing.

Gen Y have been constantly surrounded by choice and therefore do not tend to in one job for very long. They prefer constant stimulation and the opportunity to develop their skills - if these do not get it, they will walk the door and join another organization. Gen Y have a strong attitude - "what is for me". They focus on entitlements, rewards, promotion and self development. Other generation perceives them as arrogant, money minded ,selfish, lazy and unethical. However, provided with rewards, access to training and inspiring leadership, this generation will thrive and they are to take businesses through to the future. They are young, smart and brash. They may wear flip - flops to the office or listen to ipods at their desk. They want work but they do not want work to be their life. This is Generation Y which constitutes a very significant part of our population most of them have embarked in their first job career and some are trying to embark taking their place in an increasingly competitive multigenerational work place.

Therefore, Generation $\mathrm{Y}$ is different from others, in a fast changing demographic set up. They are changing jobs frequently thereby creating frustrations for employers to retain and recommit talented high performers - thus they are high performer and high maintenance. They are less likely to respond to the traditional management practices.

India's large Gen Y cohort is young and eager to learn and advance. Managing this workforce through robust development plans will be the only way that organization will reap the benefits of the dividend promised by Young India. Managers will learn what they and their organizations must do to help this cohort realize its potential. With $65 \%$ of our population under the age of 35 years India today boasts one of the largest available Gen Yworkforces in the world. This is a telling and powerful demographic truth. Even more powerful is the fact that a large segment of this demographic belongs to the Gen Y cohort, those just entering the workforce or who have been working for few years. How this generation makes transition into the workforce and how 
organizations develop and engage them to move up and make them business leaders are extremely important matters for Indian organizations today. As the organizations are becoming multi generational situation, adjustment issues leading to some frustration in the employees and emerging challenges for employees are expected. Employees in the category of Gen Y or Gen X these two are part of largest segment of employees and they are colleagues for a long time, so it is time to figure out how to engage them to achieve organizational goals and understand work values which motivate them.

In spite of generation differences, Gen $\mathrm{X}$ and $\mathrm{Y}$ have a lot in common and they can form great teams if organizations provide space to do best. Both Gen X and Y feel social responsibility, desire for work life balance, want to have fun, keep things moving, productive and forward looking. Organizations need to work on strengths of both generation. Like (a) if organization has a project that requires multi tasking and technology and organization has time to actively supervise and provide feedback - assign it to Gen Y. They want engagement. (b) If organization has a project that needs to get done and has little time for supervision - trust Gen X to take care of it. They want freedom.

When it comes to bridging generation gaps, understanding of employee engagement and their work values is the key. On the basis of various studies the following work values, work attributes and work styles have been identified for Gen X and Gen Y by various studies -

\section{Comparative Analysis of Research Findings for Generation X and Generation Y- Work Values, Work} Attributes \& Work Styles

\begin{tabular}{|c|c|c|c|c|c|}
\hline Generatio & Born & Age in 2016 & Work Values & Work Attributes & Work style \\
\hline \begin{tabular}{l|l} 
Gen X & \\
\end{tabular} & $1961-1980$ & $55-36$ & $\begin{array}{l}\text { - Contribution } \\
\text { - Reward } \\
\text { - Recognition } \\
\text { - Autonomy } \\
\text { - Involvement }\end{array}$ & $\begin{array}{l}\text { - Adoptability } \\
\text { - Independence }\end{array}$ & $\begin{array}{l}\text { - High Quality } \\
\text { - Result orientation } \\
\text { - Productivity } \\
\text { - Balance between work \& life } \\
\text { - Work to live } \\
\text { - Fexi work time } \\
\text { - Respect for authority } \\
\text { - Technically competent } \\
\text { - Ethnic diversity } \\
\text { - Intemal promotion }\end{array}$ \\
\hline Gen Y & $1980-1995$ & $36-21$ & $\begin{array}{l}\text { - Self expression } \\
\text { - Self-marketing } \\
\text { \& branding } \\
\text { - Violence prone } \\
\text { - Life style enjoyment } \\
\text { - Senior most eam respect }\end{array}$ & $\begin{array}{l}\text { - } \text { Adapt rapidly } \\
\text { - Crave change \& challenges } \\
\text { - Exceptionally resiliently } \\
\text { - Dedicated to cause } \\
\text { - Accept people with diverse strata } \\
\text { - Global in perspective }\end{array}$ & $\begin{array}{l}\text { - Want to know their role, contribution, } \\
\text { impact and importance in organization } \\
\text { - View work as self expression } \\
\text { - Exceptionally multi tasker } \\
\text { - Maintain work life balance } \\
\text { - Want flexi work hours and no dress code } \\
\text { - Seek relaxed work environment } \\
\text { - Involve in C\&R activities } \\
\text { - Seek work in teams } \\
\text { - Seek continuing leaming } \\
\text { - Want entitlement }\end{array}$ \\
\hline
\end{tabular}

To conclude, the fact that Gen $\mathrm{Y}$ will be more and more at work place in coming years, rather than criticizing them for being different and understand how managers need to look at the ways in which they are different and understand how the situation can change for business to bridging the gap. In the context of Indian organizations, Gen X and Gen Y are most critical for achieving business results. Generation gap will widen in coming times and will play a big role in business as companies must find a way to balance the needs and views of employees from differing age groups (not to mention different sex, race and culture). Also the organizations must be aware of changing demography of their employees, customer etc as generation gap have drastic effects on their business but also over all business cycle as well.

\section{References}

[1]. Achievers, (2011) How to Engage Gen X and Gen Y. www.achievers.com

[2]. Hansen, C. and Leuty, Melanic (2012) Work Values Across Generation. Journal of Career Assessment, Vol 2o, No. 1,34-52.

[3]. Nair, R . K.(2011) The Evolution of Gen Y Workforce. HRD Network Journal, Vol 1, No, 4,39-44.

[4]. Natarajan, G.(2013) Why Gen Y Should Matter to Indian Inc. http://dnaindia.com

[5]. Netra, Neelam et al.(2013) A Study of Expected Organization Values and Beliefs among Generation Y as Potential Employees . Indian Journal of Scientific Research, Vol 2, No. 5 Vol 2, No. 5 ,594-597.

[6]. Sengupta, D. et al. (2013) (20113) Gen Y Demands-What Companies are Doing to Keep Employees Happy and Motivated. Economic Times ,July ,21 